\title{
Use of Drilling Muds
}

\author{
Yulia Mikhailovna Galitskova \\ Samara state technical University \\ Architecture and construction Academy \\ Samara, Russia \\ galickova@yandex.ru
}

\begin{abstract}
Drilling of wells is accompanied by pollution of all environmental components with drilling and process waste. With drilling operations carried out, terrain and soil mass disturbance occur first. Waste generated during the drilling process includes drilling muds, return drilling muds, drilling wastewater. The contaminating ability of drilling waste is determined by the use of chemical reagents and components involved in the preparation and processing of drilling muds. The use of additives and reagents is necessary to make sure the solution displays certain properties that ensure effective well drilling. The resulting waste is usually disposed of at landfills or is buried at the site of formation in mud pits, ensuring minimal environmental impact. The use of drill muds in other spheres is hindered by the complex composition of oily waste.
\end{abstract}

The composition of liquid and solid fractions of drilling muds from several deposits were studied in laboratory setting. Waste samples were analyzed for moisture content, organic substances, oil products and other substances. According to the results of the research, measures for improving the properties of drilling muds were developed and proposed. For this purpose, an introduction of high sorption substances to the waste is proposed.

The most effective should be the use of a sorbent capable of retaining organic matters and heavy metals. The resulting homogeneous soil-like mixture can be used for land reclamation in the city areas and other settlements, when performing planning works at the initial and final stages of construction, as well as at landscaping residential areas.

Keywords-drilling mud, laboratory tests, land reclamation, waste disposal.

\section{I.INTRODUCTION}

Oil production exists and is developing in different countries of the world for more than 110-140 years. Since then, oil and gas production has increased more than 40 times. Now the new generation of drilling rigs are fully automated, equipped with robots that minimize manual labor, performing monotonous and dangerous types of work on the rig [1] - [5].

However, if the equipment, procedures and drilling technology have evolved over the years, then such byproducts of well drilling, like drilling muds, have been placed and accumulated in mud pits of the drilling sites for many years [5] - [7]. The importance of the problem lies not only in the increasing amount of waste, but also in their negative impact on all components of the natural environment [8]. Wastes significantly change the natural state of the geo-ecological environment, decrease natural resistance of groundwater, activate geochemical and geomechanical processes, and alter the natural microbiocenosis [9] - [11].

Due to the complex component composition of oily waste, the choice of its processing method is difficult. In the oil industry, research and development is carried out on the separate processing of drilling wastes, depending on the conditions of their formation, their depth and shelf life in mud pits [12] - [14]. Such an approach makes way for the rational use of wastes as secondary material resources.

Waste generated during the drilling process includes drilling muds, return drilling muds, drilling wastewater. The contaminating capacity of these wastes depends on the type of chemical reagent and the components used in the preparation and processing of drilling fluids in order to provide the solution with certain properties that contribute to more efficient drilling [15] - [17].

Most oil companies place drilling muds in mud pits on their well pads to investigate ways to convert the muds into fuel, fertilizers, and construction soil [16] - [20].

Simple backfilling of mud pits with soil after disposal, without reclamation measures, leads to an increase in anthropogenic load on the utilized area.

\section{MATERIALS AND METHODS}

The first goal of scientific research was to determine the composition of drilling muds formed on the territory of the Orenburg region. Material for studies was collected on the territory of the Tsarichansky-Filatovsky deposit of the Orenburg region, namely at the construction sites of production wells No. 526 and No. 419. This deposit is the largest discovered in the Orenburg region in recent years and one of the most problematic in terms of geology in the world. For such a challenging oil production, drilling of high-tech wells with multi-stage hydraulic fracturing is performed.

Constantly circulating drilling fluid, present in the process of drilling, brings to the surface cuttings which are later sent for temporary storage in a two-section mud pit (Fig.1). The solid fraction of the waste is separated and precipitated in the first receiving section, and the liquid components flow through the overflow pipe into the second section of the pit and are involved in the process of recycling for repetitive use of the solution. 


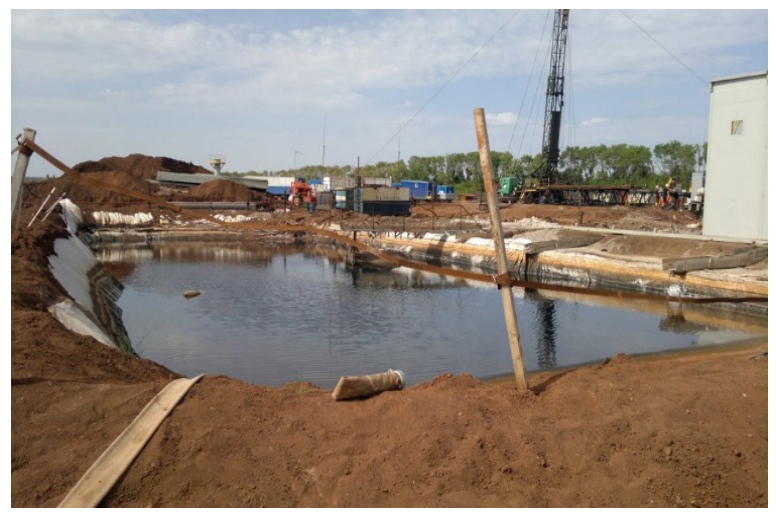

Fig. 1. The two-section mud pit.

Table 1 and 2 present the estimated volumes and masses of drilling waste generated during well construction.

table i. Estimated Mass And Volume Of Waste from Drilling Well No. 419

\begin{tabular}{|l|l|c|c|}
\hline \multirow{2}{*}{ Parameters } & \multicolumn{3}{|c|}{ Type of waste } \\
\cline { 2 - 4 } & $\begin{array}{c}\text { Drilling } \\
\text { muds }\end{array}$ & Drilling fluids & Wastewater \\
\hline volume, m3 & 357 & 751 & 1500 \\
\hline mass, tonne & 643 & 788 & 1516 \\
\hline
\end{tabular}

TABLE II.

Estimated Mass And Volume OF Waste from Drilling Well No. 526

\begin{tabular}{|l|l|c|c|}
\hline \multirow{2}{*}{ Parameters } & \multicolumn{3}{|c|}{ Type of waste } \\
\cline { 2 - 4 } & $\begin{array}{c}\text { Drilling } \\
\text { muds }\end{array}$ & Drilling fluids & Wastewater \\
\hline volume, m3 & 361 & 755 & 1511 \\
\hline mass, tonne & 651 & 793 & 1526 \\
\hline
\end{tabular}

\section{Study}

To determine the physical and chemical composition of the resulting waste muds, liquid and solid fractions of drilling waste were taken as samples. The samples were collected in several parts of the mud pit, meeting the following conditions:

- first sampling took place before the drilling mud was exposed to the atmosphere,

- second sampling took place directly in the first compartment of the mud pit, where the solid components had precipitated,

- third sampling was carried out in the second compartment of the pit where the liquid fraction had accumulated.

The solid fraction before the study and after the elimination of water and components soluble in organic solvents is presented in Fig. 2 and 3 respectively. The liquid fraction of the sample is presented in Fig. 4

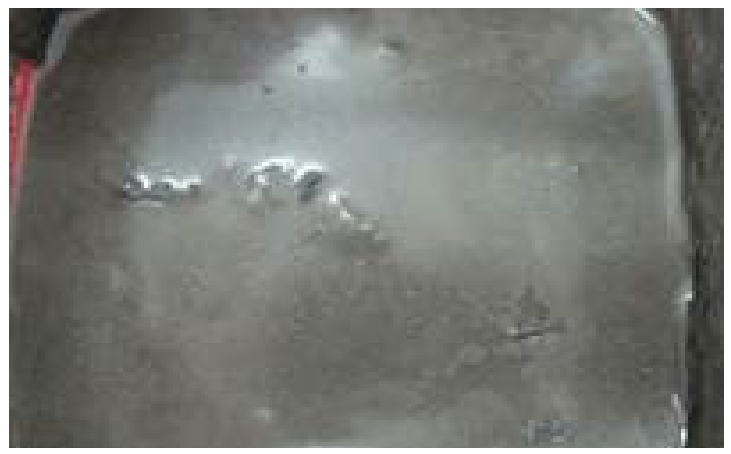

Fig. 2. The sample to conduct research.

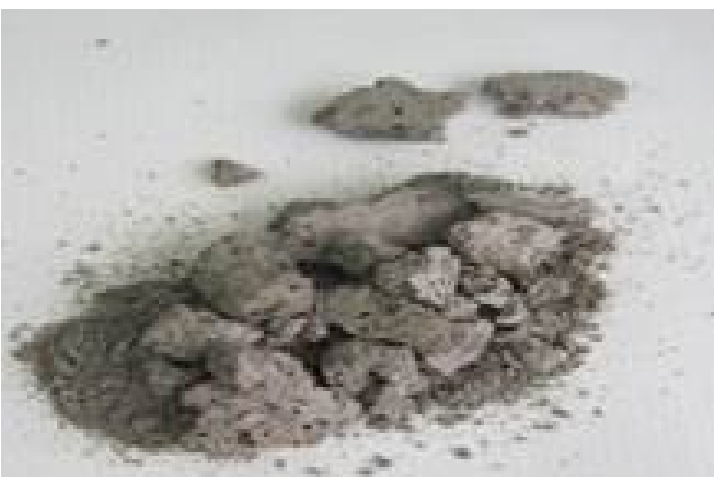

Fig. 3. The sample after the elimination of water and components soluble in organic solvents.

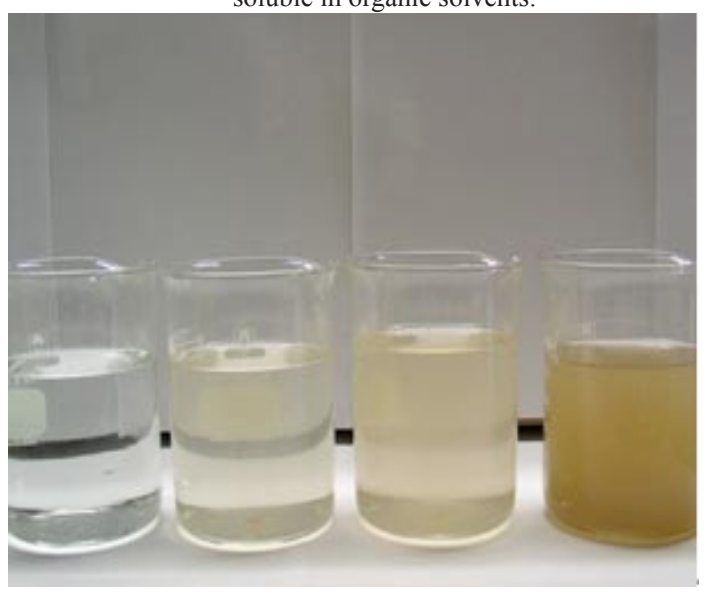

Fig. 4. The sample of liquid fraction.

III. RESULTS AND DISCUSSION

The results of chemical analysis are presented in the diagram (Fig. 5).

Based on the data obtained, the hazard class 4 of drilling waste was determined. The results of the study also showed similarity of drilling muds and surface rocks that belong to soil-forming rocks.

Therefore, the resulting drilling fluid that has undergone four-stage cleaning can be used as a feedstock for the final decontamination and formation of artificial soil.

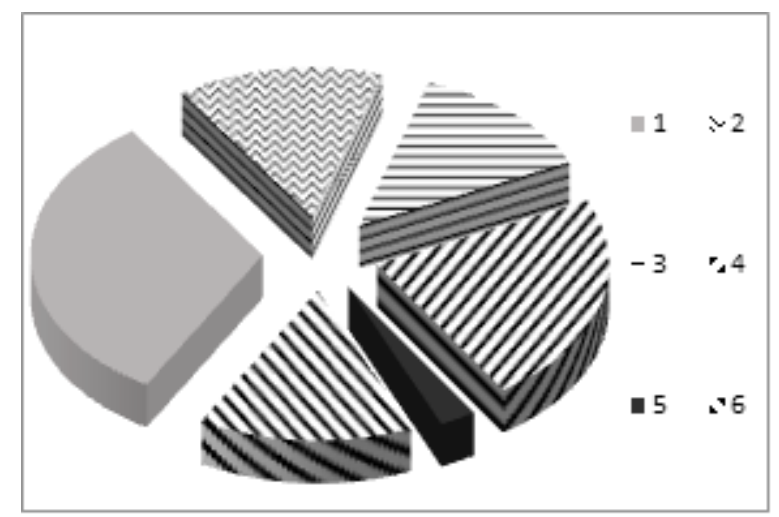

Fig. 1. The percentage of pollutants in the sample of the solid fraction of drilling muds (\%): 1 - clay, 2 - calcium chloride,

3 - magnesium chloride, 4 - calcium carbonate, 5 - magnesium carbonate, 6 - iron oxide

The utilization of such soils is possible only in the case of their transformation and decontamination by the additives that have no negative impact on the 
environment. Such substances include sorbents with high sorption capacity.

There are currently several such sorbents utilized for the disposal of drilling muds. Each has its own advantages. The comparative analysis of groups of sorbents showed that a destructive sorbent, which consists of carbon and silicon dioxide, is the most effective for the considered drilling waste. That is, the sorbent must exhibit the properties of coal and silicate adsorbents. Such a sorbent will be closest to the soil in its composition, and will allow the fixation of organic substances and heavy metals.

For these purposes, the destructive sorbent СД-1 was analyzed. It has no artificial biodestructive microorganisms in its composition. The oxidative activity of the sorbent helps to improve the conditions for the development of the local natural community of biodestructive species.

To apply the recommended method of disposal of drilling wastes, we advise to analyze the possibility of building a drill hole (at the preparatory stage) to determine the feasibility of using this treatment technology. The next recommendation is to provide a compartment directly in the mud pit for further mixing of the drilling fluid with the reagent. At the final stage of drilling waste treatment, it is recommended to conduct intermediate monitoring of the condition and composition of the obtained soil. After all the necessary decontamination processes have taken place, a fertile layer of $10-20 \mathrm{~cm}$ thick is created on the reclaimed surface.

\section{CONClusions}

To develop measures to reduce the negative impact of drilling wastes on the environment, to decrease the utilized volumes of drilling fluids, studies were conducted on the composition of the liquid and solid fractions of the resulting drilling wastes at several drilling sites in the Orenburg region.

Based on the presented research results, possible options for drilling waste disposal were analyzed to determine the most optimal solution.

The recommendation is to use a sorbent, which allows both to decontaminate drilling fluids and decrease their hazardousness from class 4 to class 5 , and also to obtain artificial soil without hazardous properties.

The resulting soil mixture can serve as a mineral base for the fertile layer when carrying out biological reclamation, as a backfill at construction sites, in the course of construction and finishing of field roadways and field sites, as well as for reclaiming and backfilling of open pits, trenches and other types of works that make use of traditional soil.

Since, while being processed, the hazard class of drilling muds goes down to 5, and the muds have no negative impact on the environment, the resulting soil may be used in the planning of construction sites of settlements, as well as in land reclamation.

The economic effect from the use of sorbent (data calculated for one well) is approximately 5 million rubles.

\section{REFERENCES}

[1] J. Järnegren, S. Brooke, H. Jensen, "Macrofaunal communities associated with chemosynthetic habitats from the U.S. Atlantic margin: A comparison among depth and habitat types," in DeepSea Research Part II: Topical Studies in Oceanography vol. 137, 2017, pp. 42-55.

[2] A.I. Murzayeva, Y.M. Galitskova, "Urban soil contamination Procedia Engineering, “vol. 153, 2016, pp.162-166.

[3] R.A. Savinov, A.V. Kalashnikov, D.A. Konuhov, A.V. Petrov, "Analysis and modernization of well drilling waste utilization methods," in Environmental protection in oil and gas complex vol. 8, 2011.

[4] A.A. Annenkov, V.A. Grabovnikov, N.N. Egorov, "Drilling waste management methods in the process of exploration and development of oil and gas fields," in Exploration and protection of mineral resources vol. 10, 2013, pp.4.

[5] I.A. Bobrenko, E.U. Pavlova, "The problem of improving environmental safety in treatment of drilling wastes on the territory of Western Siberia, " Omsk scientific Bulletin vol. 1, 2015,pp. 198-202.

[6] N.V. Stolbova, A.A. Matsuk, E.A. Shafeeva, "Actual problems of drilling waste disposal," in Science and technology in gas industry vol. 1, 2011, pp.96-99.

[7] V.A. Gureva, V.V. Dubinetsky, K.M. Vdovin, "Environmental and economic effects of sludge in the production of ceramic bricks," in International research journal, vol. 11, 2016, pp.50-53. DOI: https://doi.org/10.18454/IRJ.2016.53.002

[8] E. A. Pichugin, "Technology Solution for Waste Recovery of Gel Breakdown in Aqueous Bases after Hydraulic Fracturing," in Ecology and industry of Russia vol. 7, 2017, pp.30-35.

[9] N.L. Zotsenko, E.A. Timofeeva, "A sludge pit for drilling wastes of oil and gas wells with soilcement watertight screens," in Bulletin of Perm national research Polytechnic University. Construction and architecture vol. 1, 2015, pp.7-20. https://doi. org/10.15593/2224-9826/2015.1.01

[10] E. A. Pichugin, "Drilling mud as a component of reclamation materials," in Ecology and industry of Russia, vol. 4, 2018, pp. 16-19.

[11] A. E. Rakhmetova, E. I. Kutuzova, "Production waste during drilling and drill cuttings," in Young scientist, vol. 3, 2018, pp. 59-61.

[12] V.S. Petukhova, L.N. Skipin, D.L. Skipin, "Comparative assessment of alternatives for biological restoration of drill cuttings," in Agrarian Bulletin of the Urals, vol.1, 2017, pp. 8.

[13] M.V. Zilberman, E.A. Pichugin, M.V. Cherepanov, B.E. Shenfeld, G.A.Kozlova, "Brill cuttings properties and possible directions of their disposal," in Bashkir environmental Bulletin, vol.2, 2013, pp.10-14.

[14] M. M. Malyshkin, "Greening the technology of drilling wells, " in Proceedings of the Mining Institute, vol.203, 2013, pp. 63-66.

[15] N. V. Stolbova, A. A. Matsuk, E. A. Shafeev, “Actual problems of drilling waste disposal," in Science and technology in the gas industry, vol.1, 2011, pp. 96-99.

[16] M. R. Meretukova, "Confirmation of suitability for use in construction of drill cuttings according to studies," in Drilling and oil, vol.12, 2016, pp. 36-37.

[17] D. V. Oreshkin, G. P. Sakharov, A. N. Chebotaev, A. S. "Kurbatova, Geo-ecological problems of drilling waste disposal in the yamal peninsula," in Vestnik MGSU, vol. 2, 2012, pp. 125-129.

[18] L. N. Skipin, Skipin D. L., V. S. Petukhov, I. N. Kustysheva, "The effects of coagulant on the physical properties of drill cuttings," in Bulletin of Kemerovo state University, vol. 4, 2015, pp. 88-92.

[19] E. A. Timofeev, N. D. Kuramshina, "The drilling waste slurry in the barn," in Youth and science, vol. 2, 2018, pp. 118.

[20] T. N. Zhukov, I. S. Glushankova, E. S. Belik, "DeVelopment of technology for disposal waste drilling fluids, drilling sludges and oil-contaminated soils using biological products," in Transport. Transport construction. Ecology, Vol. 2, 2015, pp. 31-45. 